Canadian

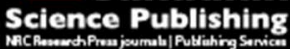

Applied Physiology, Nutrition, and Metabolism Physiologie appliquée, nutrition et métabolisme

\title{
Words matter: Reframing Exercise is Medicine for the general population to optimize motivation and create sustainable behaviour change
}

\begin{tabular}{|r|l|}
\hline Journal: & Applied Physiology, Nutrition, and Metabolism \\
\hline Manuscript ID & apnm-2016-0125.R2 \\
\hline Manuscript Type: & Current opinion \\
\hline Complete List of Authors: & $\begin{array}{l}\text { Fortier, Michelle; University of Ottawa } \\
\text { Guérin, Eva; Institut de recherche de I'Hôpital Montfort , ; University of } \\
\text { Ottawa, } \\
\text { Segar, Michelle; University of Michigan, Sport, Health, and Activity } \\
\text { Research and Policy (SHARP) Center }\end{array}$ \\
\hline Keyword: & $\begin{array}{l}\text { physical activity < exercise, biopsychology < biopsychology, exercise } \\
\text { therapy < exercise, physical inactivity < exercise, medicine }\end{array}$ \\
\hline \multicolumn{2}{|c}{} \\
\hline
\end{tabular}

SCHOLARONE

Manuscripts 
RUNNING HEAD: Words matter: Reframing EIM

Applied Physiology, Nutrition, and Metabolism

Words matter:

Reframing Exercise is Medicine for the general population to optimize motivation and create sustainable behaviour change

Michelle Fortier**1, Eva Guérin ${ }^{2}$, Michelle L. Segar ${ }^{3}$

${ }^{1}$ School of Human Kinetics, University of Ottawa; 125 University Pr. Ottawa, ON, K1N 1A2;

Tel: 613-562-5800 Ext. 4275; Fax: (613) 562-5149; Email: mfortier@uottawa.ca.

${ }^{2}$ Institut de Recherche de l'Hôpital Montfort;

202-745A Montréal Rd, Ottawa ON, K1K 0T1; Email: eva.eg.guerin@gmail.com

${ }^{3}$ University of Michigan; Sport, Health, and Activity Research and Policy (SHARP) Center;

1122 Lane Hall 1109, Ann Arbour, MI 48109; Email: fitness@umich.edu.

*Corresponding Author 


\begin{abstract}
Exercise is medicine (EIM) is grounded in strong evidence regarding the benefits of physical activity. Despite the contributions of EIM initiatives worldwide, rates of physical inactivity remain alarmingly high. We propose a reframe of EIM for the general population to improve motivation and foster sustainable behaviour change. We draw on a solid knowledge-base to explain the value of broadening the nomenclature to physical activity and of promoting a message of well-being via enjoyable physical activity.

Keywords: physical activity, biopsychology, exercise therapy, physical inactivity, medicine
\end{abstract}




\section{Introduction}

Launched in the United States in 2007, Exercise is Medicine (EIM) is a laudable initiative that extends to over 40 countries. Exercise is Medicine Canada (EIMC) began in 2012 with the vision that "Physical activity is an integral part of prevention and treatment of chronic disease in the Canadian health care system". Exercise is Medicine is based on exceptionally strong evidence showing that regular exercise has multiple and significant benefits (Humphreys et al. 2014). For instance, a meta-epidemiological study that included 305 randomised controlled trials concluded that exercise had similar effectiveness to drug interventions for several chronic diseases (Naci and Ioannidis 2013). Moreover, in a cohort study tracking 334161 Europeans over 12.4 years, physical activity (PA) levels were a better predictor of mortality than BMI or waist circumference (Ekelund et al. 2015). At the highest level of evidence, Wegner et al. (2014) reviewed 37 meta-analyses to reveal a strong effect of exercise on depression (et al. 2014).

The various EIM initiatives, which either target health care professionals (HCP) or the general public, have made important real-world impacts. In Canada, innovations like "EIM on campus" and a PA prescription tool for physicians accompanied by nation-wide workshops have been implemented (Frémont et al., 2014). While it is likely that the EIM campaign has moved the needle in terms of PA awareness among HCP, the authors are unaware of rigorous evaluations regarding its effectiveness in increasing exercise prescription or population physical activity rates per se.

What we do know, however, is that our work to get people moving could be improved given that population-level PA rates remain low. In fact, as many as $80 \%$ of Canadians are insufficiently active to achieve health benefits (Colley et al. 2011). These alarming statistics highlight that current EIM endeavours directly and indirectly geared towards the general 
population could be refined to help improve PA levels. The purpose of this paper is to encourage proponents of EIM to think more deeply about their messaging in their attempts to activate the general population. We propose that EIM work on the way its information is shared, both when it is translated by HCP to patients and in media campaigns geared towards the masses. While EIM might be a valuable concept for inspiring HCP to address PA (Sallis 2015), there are evidence-based reasons why it may not be an optimal term for the general public. In this paper we provide evidence-based reasons why HCP and broader EIM messaging should frame 'moving' as PA that promotes enjoyment and well-being rather than exercise is medicine.

\section{Physical activity is more inclusive than exercise}

Whereas exercise is a type of PA defined as movement that is planned, structured and repetitive with the objective of maintaining/improving fitness, physical activity is broader in scope and is defined as movement of the body that results in energy expenditure (Caspersen et al. 1985). As a result of being overly narrow in nature and scope, exercise does not encompass many activities that people could engage in, such as gardening, hiking with a friend or going for a family bike ride. By emphasizing the term exercise, EIM is limited to only certain forms of PA despite research showing that most forms of PA provide physical and mental health benefits (Humphreys et al. 2014).

Our proposed reframing of exercise to PA for the general population is in line with that of current PA guidelines (Tremblay et al. 2011) as well as research regarding people's beliefs about exercise. For instance, given the choice between a structured training facility/gym in which to exercise or engaging in lifestyle-forms of PA such as walking, many individuals prefer the latter (e.g., Dunn et al. 1999). This is substantiated by recent Canadian statistics showing that adults participate in physical activities such as walking (84\%) and gardening/yardwork (74\%) more 
frequently than exercise such as weight training (41\%) (CFLRI, 2015). In fact, casual PA like walking confers several advantages including low cost, minimal risk, and ease of scheduling. Furthermore, studies have shown that the term "exercise" is viewed negatively by many, including at-risk individuals such as elderly women (e.g., Milne et al. 2014), which likely prevents EIM messages from reaching the people in greatest need of becoming physically active.

Moreover, research shows that people have different preferences vis-à-vis the form of PA they want to do (Parfitt and Hughes 2009); studies have revealed that allowing people to choose which type of PA they engage in facilitates motivation and adherence (e.g., Rose and Parfitt 2012). This very notion of choice aligns with motivation frameworks that offer insights regarding why people sustain health behaviours like PA and how this benefits their well-being.

\section{Enjoyable physical activity is a powerful motivator}

Self-determination theory (Deci and Ryan 1985) posits that people engage in pursuits like PA for different reasons. Some are considered optimal because they are self-determined, for instance being active because it aligns with one's life goals and/or is pleasurable (i.e., intrinsic motivation). Conversely, some reasons are deemed non-optimal because they are controlled/not self-determined, such as following doctors' orders to exercise, avoiding guilt for not moving, or pursuing weight loss to improve appearance. A systematic review showed that self-determined reasons and especially intrinsic motivation/for enjoyment lead to long term PA maintenance (Teixeira et al. 2012).

Likewise, interventions that foster enjoyable PA experiences have yielded positive findings with respect to lasting behaviour change (Fortier et al. 2012). We concur with Segar and Richardson (2014) that promoting PA as something pleasurable and potentially meaningful is an underutilized yet scientifically supported strategy for motivating the general population. 
Promoting PA as a way to generate enjoyment is especially important to consider given that the majority of adults live hectic, time-pressed lives and are more likely to fit movement into their life if it feels good.

Research has also shown that intrinsic motivation tends to be higher among individuals who are self-compassionate (Magnus et al. 2010). Self-compassion is an evidence-based concept that is defined as treating the self with kindness and understanding (Neff 2011). Studies suggest that self-compassion is related to better motivation, less fear of failure and higher well-being (Neff 2011). Indeed, self-compassion encourages positive emotions necessary to maintain motivation during the pursuit of health goals like PA (Sirois et al. 2015). Being selfcompassionate also reflects being self-aware and respecting ones limits. Thus, a selfcompassionate approach to being physically active gives people permission to engage in activities that are enjoyable and feel good to them, at a level of exertion that is comfortable to maintain.

In fact, the issue of exertion (or "dosage") is particularly relevant to how we frame PA. Literature reveals that when people (not athletes) are given the choice between longer durations of less intense PA versus more vigorous workouts, many prefer the former as they tend to achieve more positive emotional benefits (Kilpatrick et al. 2007). Furthermore, research shows that high intensity movement tends to increase displeasure, which negatively reinforces on-going decisions to be active (Ekkekakis et al. 2011). Conversely, positive emotions derived from PA have been shown to lead to behavioural persistence 6 and 12 months later (Williams et al. 2008). Because people avoid what feels bad and approach what feels good (Petruzzello 2012), our suggestions/messages to the general population about being physically active should include feelings of pleasure as an important criterion. 
Regrettably, scientifically-supported principles of enjoyable less intense PA participation have not been the dominant message in society nor within the EIM movement. In fact, the opposite trend is occurring, emphasizing high intensity and extreme athleticism. The emergence of "HITT" (i.e., High Intensity Interval Training), the increased registration to marathons/triathlons, and the appearance of extreme events such as ultra-marathons attest to this (Hoffman et al. 2010). Unfortunately such events and images create a daunting standard for the inactive and likely dissuade beginners who do not identify with this type of athleticism and more importantly do not feel capable of- or desire to- engage in PA at that level.

In general, the "more PA is better" discourse, while well-intended, might inadvertently guide the general population to engage in PA in ways they think they should rather than in ways that feel good, making them less likely to sustain this behaviour. For example, the Canadian PA guidelines explicitly state that even when meeting the 150 minutes/week recommendation (Tremblay et al. 2011) "more physical activity provides greater health benefits". Still, much of the population has been unable to attain even these basic recommendations after decades of promotion (Colley et al. 2011). While the "more PA is better" principle is based on a solid doseresponse evidence-base in disease management (Arem et al. 2015) and is true for certain people and under certain circumstances (Naci and Ioannidis 2013), delivering this message as a benchmark has the potential to misguide many people, particularly the novice, who then might engage in PA in ways that will thwart self-determination/enjoyment and could even lead to injury. In fact, this message is challenged by an emerging literature showing that too much PA is not optimal for physical and mental health (Thomas and Heymsfield 2016). For instance, too much PA/sport in youth has been associated with lower mental health, more injuries and other health problems (Bean et al. 2014). According to Eijsvogels and Thompson (2015), vigorous PA 
in healthy individuals may attenuate health benefits and in patients with cardiovascular disease, high doses are associated with increased mortality risks. Too much PA can also lead to lower quality of life (Brown et al. 2004).

Furthermore, there is sufficient evidence showing that less PA is needed to reap psychological benefits than may be required for physical gains. For example, a systematic review showed that low-to-moderately intense PA, 2-3 times per week for several weeks can help relieve depression symptoms (Silveira et al. 2013). Therefore, messaging that suggests that more (or more vigorous) PA is always better has the potential to mislead individuals and may even promote the avoidance of PA all together. We recommend health/exercise professionals help their clients to self-select their format of PA as well as their preferred intensity to optimize enjoyment and ensuing maintenance.

\section{Well-being is a better "hook" than medicine}

There are several reasons why well-being is a better hook to be active than medicine for the general population. Let's consider the difference between the underlying meaning of wellbeing compared to medicine. Typically, it is only the ill who take medicine when both the ill and the healthy benefit from being physically active. Thus, by using the term medicine, we imply that exercise is for those who are sick. In addition, taking medication not only reflects a negative symbolism that might mean a bitter taste or painful experience, but something that is prescribed to people rather than a choice that people make on their own accord.

In contrast to medicine, well-being is a broad concept that features physical and mental health dimensions that are positively impacted by PA (Guerin 2012). Well-being, an inherently positive consequence, is likely to be more appealing, uplifting and energizing to the general population than the health benefits inferred by a medicine metaphor. Importantly, fostering well- 
being is considered by experts in chronic disease management as what best motivates people to follow their treatment regimen (Landro 2012). There is a growing body of evidence to support this contention. As an example, one study reported that PA goals aiming to enhance daily quality of life were associated with more PA over one year than goals aiming to achieve better health or healthy aging (Segar et al. 2011). Similarly, research is mounting showing that messages featuring affective - feel good benefits consistently result in higher participation than healthrelated ones (Conner et al. 2011).

Overall, traditional PA promoting messages (including EIM) have focused predominantly on medical, physical/weight-loss, and disease-related benefits (see discussion by Bailey 2013). While some research has shown positive effects of mass media campaigns that originate from a medical perspective (Wakefied et al., 2010), they have evidently not succeeded in changing population PA levels. By primarily targeting patients with advertisement messaging such as "Add years to your life...150 minutes of exercise a week reduces your risk of death by treating,

preventing heart disease....", EIM is also perpetuating the medicalization of PA. While EIM rose from strong evidence showing that PA benefits physical health, it is crucial that its proponents (including HCP) understand that what they care about achieving may not be congruent with what will optimally motivate the individuals they hope to influence.

\section{Conclusion}

We propose that EIM could better activate the population by reframing PA as an optimal way of experiencing enjoyment and enhancing well-being, doing so via education, tools and other resources to the public and in workshops/training to HCP. In this paper we provided reasons and evidence for what we believe is a more strategic frame to hook the general population and which will be more motivating to the end-users targeted by this initiative, the 
nearly 29 million insufficiently active Canadians. This improved communication scheme better reflects a growing evidence base about what drives motivation, decision making, and sustainable participation. Finally, EIM may benefit from partnering with health promotion departments and organizations (e.g., ParticipACTION) to support a message of enjoyable PA for well-being so that all might row together to turn this physical inactivity ship around.

\section{Conflict of interest}

The authors report no conflicts of interest associated with this manuscript.

MLS wishes to disclose that she has an organizational consulting and training company and coaches individuals in how to sustain self-care behaviours. 


\section{References}

Arem et al. 2015. Leisure Time Physical Activity and Mortality: A Detailed Pooled Analysis of the Dose-Response Relationship. JAMA Intern Med. 2015 Jun 1;175(6):959-967. doi: 10.1001/jamainternmed.2015.0533.

Bailey, R. 2013. Physical activity: An underestimated investment in human capital? J Phys Act Health. 10: 289-303.

Bean, C.N., Fortier, M.S., Post, C., and Chima, K. 2014. Understanding how organized youth sport may be harming individual players within the family unit: A literature review. Int. J. Environ. Res. Public Health. 11(10): 10226-10268.doi:10.3390/ijerph111010226.

Brown, D.W., Brown, D.R., Heath, G.W., Balluz, L., Giles, W.H., Ford, E.S., and Mokdad, A.H. 2004. Associations between physical activity dose and health-related quality of life. Med. Sci. Sports Exerc. 36(5): 890-896.doi:10.1249/01.MSS.0000126778.77049.76.

Canadian Fitness and Lifestyle Research Institute (CFLRI). 2016. 2014-2015 Physical Activity Monitor. Bulletin 7. CFLRI, Ottawa, ON.

Caspersen, C.J., Powell, K.E., and Christenson, G.M. 1985. Physical activity, exercise, and physical fitness: definitions and distinctions for health-related research. Public Health Rep. 100(2): 126-131.

Colley, R.C., Garriget, D., Janssen, I., Craig, C.L., Clarke, J., and Tremblay, M.S. 2011. Physical activity of Canadian adults: Accelerometer results from the 2007 to 2009 Canadian Health Measures Survey. Health Reports. 22(1): 7-14.

Conner, M., Rhodes, R.E., Morris, B., McEachan, R., and Lawton, R. 2011. Changing exercise through targeting affective or cognitive attitudes. Psychol. Health. 26(2): 133-149. doi:10.1080/08870446.2011.531570. 
Deci, E.L., and Ryan, R.M. 1985. Intrinsic motivation and self-determination in human behavior. Plenum: New York, NY.

Dunn, A.L., Marcus, B.H., Kampert, J.B., Garcia, M.E., Kohl, H.W., and Blair, S.N. 1999. Comparison of lifestyle and structured interventions to increase physical activity and cardiorespiratory fitness: a randomized trial. JAMA. 281(4): 327-334.doi:101001/pubs.JAMA-ISSN-0098-7484-281-4-joc80889.

Eijsvogels, T.M.H., and Thompson, P.D. 2015. Exercise is medicine: At any dose? JAMA. 314(18): 1915-1916.doi:10.1001/jama.2015.10858.

Ekelund, U., Ward, H.A., Norat, T., Luan, J., May, A.M., Weiderpass, E. et al. 2015. Physical activity and all-cause mortality across levels of overall and abdominal adiposity in European men and women: the EPIC Study. Am. J. Clin. Nutr. 101(3): 613-621. doi:10.3945/ajen.114.100065.

Ekkekakis P, Parfitt G, and Petruzzello SJ. 2011. The pleasure and displeasure people feel when they exercise at different intensities: decennial update and progress towards a tripartite rationale for exercise intensity prescription. Sports Med. 41(8):641-71. doi: $10.2165 / 11590680$.

Frémont, P., Fortier, M.S., and Frankovich, R.J. 2014. Exercise prescription and referral tool to facilitate brief advice to adults in primary care. Can. Fam. Physician. 60(12): 1120-1122.

Fortier, M.S., Duda, J.L., Guerin, E., and Teixera, P.J. 2012. Promoting physical activity: development and testing of self-determination theory-based interventions. Int. J. Behav. Nutr. Phys. Act. 9(1): 20.doi: 10.1186/1479-5868-9-20. 
Guérin, E. 2012. Disentangling vitality, well-being, and quality of life: A conceptual examination emphasizing their similarities and differences with special application in the physical activity domain. J. Phys. Act. Health. 9(6): 896-908.

Hoffman, M.D., Ong, J.C., and Wang, G. 2010. Historical analysis of participation in 161 km ultramarathons in North America. Int. J. Hist. Sport. 27(11): 1877-1891. doi:10.1080/09523367.2010.494385.

Humphreys, B.R., McLoed, L., and Ruseski, J.E. 2014. Physical activity and health outcomes: Evidence from Canada. Health Econ. 23(1): 33-54.doi:10.1002/hec.2900.

Kilpatrick, M., Kraemer, R., Bartholomew, J., Acevedo, E., and Jarreau, D. 2007. Affective responses to exercise are dependent on intensity rather than total work. Med. Sci. Sports Exerc. 39(8): 1417-1422.doi:10.1249/mss.0b013e31806ad73c.

Landro L. 2012. The simple idea that is transforming health care [online]. Available from http://online.wsj.com/article/SB10001424052702304450004577275911370551798.html. [accessed 16 February 16 2016].

Magnus, C.M.R., Kowalski, K.C., and McHugh, T.F. 2010. The role of self-compassion in women's self-determined motives to exercise and exercise-related outcomes. Self Identity. 9(4): 363-382.doi:10.1080/15298860903135073.

Milne, M., Divine, A., Hall, C., Gregg, M., and Hardy, J. 2014. Non-participation: How age influences inactive women's views of exercise. J. Appl. Biobehav. Res. 19(3): 171-191. doi:10.1111/jabr.12024.

Naci, H., and Ioannidis, J.P.A. 2013. Comparative effectiveness of exercise and drug interventions on mortality outcomes: Metaepidemiological study. BMJ Open. Available from http://www.bmj.com/content/347/bmj.f5577.full [accessed 16 February 2016]. 
Neff, K.D. 2011. Self-compassion: The proven power of being kind to yourself. William Morrow: New York NY

Parfitt, G., and Hughes, S. 2009. The exercise intensity-affect relationship: Evidence and implications for exercise behavior. J. Exerc. Sci. Fit. 7(2): S34-S41.doi:10.1016/S1728869X(09)60021-6.

Petruzzello, S.J. 2012. Doing what feels good (and avoiding what feels bad) — a growing recognition of the influence of affect on exercise behavior. Ann Behav Med. 44(1):7-9. doi: $10.1007 / \mathrm{s} 12160-012-9374-5$.

Rose, E.A., and Parfitt, G. 2012. Exercise experience influences affective and motivational outcomes of prescribed and self-selected intensity exercise. Scand. J. Med. Sci. Sports. 22(2): 265-277.doi:10.1111/j.1600-0838.2010.01161.x.

Sallis, R. 2015. Exercise is medicine: a call to action for physicians to assess and prescribe exercise. Phys. Sportsmed. 43(1): 22-26. doi:10.1080/00913847.2015.1001938.

Segar, M.L., and Richardson, C.R. 2014. Prescribing pleasure and meaning: Cultivating walking motivation and maintenance. Am. J. Prev. Med. 47(6): 838-841. doi:10.1016/j.amepre.2014.07.001.

Segar, M.L., Eccles, J.S., and Richardson, C.R. 2011. Rebranding exercise: closing the gap between values and behavior. Int. J. Behav. Nutr. Phys. 8(94): 21884579. doi: $10.1186 / 1479-5868-8-94$

Silveira H., Moraes H., Oliveira N., Coutinho E.S.F., Laks J., and Deslandes A. 2013. Physical exercise and clinically depressed patients: A systematic review and meta-analysis. Neuropsychobiology. 67(2): 61-68.doi: 10.1159/000345160. 
Sirois, F.M., Kitner, R., \& Hirsch, J.K. (2015). Self-compassion, affect, and health-promoting behaviors. Health Psychol. 34(6): 661-119.

Teixeira, P.J., Carraça, E.V., Markland, D., Silva, M.N., and Ryan, R.M. 2012. Exercise, physical activity, and self-determination theory: A systematic review. Int. J. Behav. Nutr. Phys. Act. 9(1): 78.doi: 10.1186/1479-5868-9-78.

Thomas, D.M., and Heymsfield, S.B. 2016. Exercise: Is more always better? Curr. Biol. 26(3): R102-R104. doi:10.1016/j.cub.2015.12.031.

Tremblay, M. S., Warburton, D. E. R., Janssen, I., Paterson, D. H., Latimer, A. E., Rhodes, R. E., et al. 2011. New Canadian Physical Activity Guidelines. Appl. Physiol. Nutr. Metab. 36(1): 36-46. http://doi.org/10.1139/H11-009.

Wakefield, M. A, Loken, B., Hornik, R. C. 2010. Use of mass media campaigns to change health behaviour. Lancet. 376(9748):1261-1271/

Wegner, M., Helmich, I., Machado, S., Nardi, A. E., Arias-Carrion, O., and Budde, H. 2014. Effects of exercise on anxiety and depression disorders: review of meta-analyses and neurobiological mechanisms. CNS Neurol. Disord. Drug. Targets. 13(6): 1002-1014. doi:10.2174/1871527313666140612102841.

Williams, D.M., Dunsiger, S., Ciccolo, J.T., Lewis, B.A., Albrecht, A.E., and Marcus, B.H. 2008. Acute affective response to a moderate-intensity exercise stimulus predicts physical activity participation 6 and 12 months later. Psychol. Sport. Exerc. 9(3): 231-245. doi:10.1016/j.psychsport.2007.04.002. 